\title{
Exocrine Gland
}

National Cancer Institute

\section{Source}

National Cancer Institute. Exocrine Gland. NCI Thesaurus. Code C12712.

A gland from which secretions reach a free surface of the body by ducts. 